\title{
Introduction to Behavioral Addictions
}

\author{
Jon E. Grant ${ }^{1}$, Marc N. Potenza ${ }^{2}$, Aviv Weinstein ${ }^{3}$, and David A. Gorelick ${ }^{4}$ \\ ${ }^{1}$ University of Minnesota School of Medicine, Minneapolis, Minnesota, USA \\ ${ }^{2}$ Yale University School of Medicine, New Haven, Connecticut, USA \\ ${ }^{3}$ Hadassah University Hospital, Jerusalem, Israel \\ ${ }^{4}$ Intramural Research Program, National Institute on Drug Abuse, NIH, Baltimore, MD
}

\begin{abstract}
Background-Several behaviors, besides psychoactive substance ingestion, produce short-term reward that may engender persistent behavior despite knowledge of adverse consequences, i.e., diminished control over the behavior. These disorders have historically been conceptualized in several ways. One view posits these disorders as lying along an impulsive-compulsive spectrum, with some classified as impulse control disorders. An alternate, but not mutually exclusive, conceptualization considers the disorders as non-substance or "behavioral" addictions.
\end{abstract}

Objectives-Inform the discussion on the relationship between psychoactive substance and behavioral addictions. Methods: We review data illustrating similarities and differences between impulse control disorders or behavioral addictions and substance addictions. This topic is particularly relevant to the optimal classification of these disorders in the forthcoming fifth edition of the American Psychiatric Association Diagnostic and Statistical Manual of Mental Disorders.

Results-Growing evidence suggests that behavioral addictions resemble substance addictions in many domains, including natural history, phenomenology, tolerance, comorbidity, overlapping genetic contribution, neurobiological mechanisms, and response to treatment, supporting the DSM-V Task Force proposed new category of Addiction and Related Disorders encompassing both substance use disorders and non-substance addictions. Current data suggest that this combined category may be appropriate for pathological gambling and a few other better studied behavioral addictions, e.g., Internet addiction. There is currently insufficient data to justify any classification of other proposed behavioral addictions.

Corresponding author: Dr. David A. Gorelick, 251 Bayview Boulevard, Baltimore, MD 21224, Phone: 443-631-8004; dgorelic@intra.nida.nih.gov.

Author Disclosures: All authors reported no conflict of interest regarding the content of this paper. Dr. Grant has received research grants from NIMH, NIDA, National Center for Responsible Gaming and its affiliated Institute for Research on Gambling Disorders, and Forest Pharmaceuticals. Dr. Grant receives yearly compensation from Springer Publishing for acting as Editor-in-Chief of the Journal of Gambling Studies, has performed grant reviews for NIH and the Ontario Gambling Association, has received royalties from Oxford University Press, American Psychiatric Publishing, Inc., Norton Press, and McGraw Hill, has received honoraria from Indiana University Medical School, University of South Florida, the Mayo Medical School, the California Society of Addiction Medicine, the State of Arizona, the State of Massachusetts, the State of Oregon, the Province of Nova Scotia, and the Province of Alberta. Dr. Grant has received compensation as a consultant for law offices on issues related to impulse control disorders. Dr. Potenza has received financial support or compensation for the following: consultant for and an advisor to Boehringer Ingelheim; financial interests in Somaxon; research support from the National Institutes of Health, Dept. of Veterans Affairs, Mohegan Sun Casino, National Center for Responsible Gaming and its affiliated Institute for Research on Gambling Disorders, and Forest Laboratories; has participated in surveys, mailings or telephone consultations related to drug addiction, impulse control disorders or other health topics; has consulted for law offices on issues related to addictions or impulse control disorders; has provided clinical care in the Connecticut Department of Mental Health and Addiction Services Problem Gambling Services Program; and has generated books or book chapters for publishers of mental health texts. Dr. Weinstein has received research grants from the Israeli Anti-Drug Authority, the Israel National Institute for Psychobiology, the Chief Scientist of the Israeli Ministry of Health, and the Rashi Trust (Paris, France) and fees for lectures on drug addiction from the Israeli Ministry of Education. Dr. Gorelick reports no outside funding or conflicts of interest. 
Conclusions and Scientific Significance-Proper categorization of behavioral addictions or impulse control disorders has substantial implications for the development of improved prevention and treatment strategies.

\section{Keywords}

behavioral addiction; classification; diagnosis; impulse control disorder; substance use disorder; compulsivity; drug abuse; impulisivity

\section{Introduction}

Several behaviors, besides psychoactive substance ingestion, produce short-term reward that may engender persistent behavior despite knowledge of adverse consequences, i.e., diminished control over the behavior. Diminished control is a core defining concept of psychoactive substance dependence or addiction. This similarity has given rise to the concept of non-substance or "behavioral" addictions, i.e., syndromes analogous to substance addiction, but with a behavioral focus other than ingestion of a psychoactive substance. The concept of behavioral addictions has some scientific and clinical heuristic value, but remains controversial. Issues around behavioral addictions are currently being debated in the context of development of DSM-V $(1,2)$

Several behavioral addictions have been hypothesized as having similarities to substance addictions. The current Diagnostic and Statistical Manual, $4^{\text {th }}$ Edition (DSM-IV-TR) has designated formal diagnostic criteria for several of these disorders (e.g., pathological gambling, kleptomania), classifying them as impulse control disorders, a separate category from substance use disorders. Other behaviors (or impulse control disorders) have been considered for inclusion in the forthcoming DSM - compulsive buying, pathologic skin picking, sexual addiction (non-paraphilic hypersexuality), excessive tanning, computer/ video game playing, and internet addiction. Which behaviors to include as behavioral addictions is still open for debate (3). Not all impulse control disorders, or disorders characterized by impulsivity, should be considered behavioral addictions. Although many of the impulse control disorders (e.g., pathological gambling, kleptomania) appear to share core features with substance addictions, others, such as intermittent explosive disorder, may not. In the hope of contributing to this debate, this paper reviews the evidence for similarities between behavioral addictions and substance use disorders, their distinction from obsessive compulsive disorder, and identifies areas of uncertainty warranting future research. It also serves as an introduction to the succeeding papers in this issue, which review some putative addictive behaviors in more detail.

\section{Common Features of Behavioral Addictions: Relationship to Substance Use Disorders}

The essential feature of behavioral addictions is the failure to resist an impulse, drive, or temptation to perform an act that is harmful to the person or to others (4). Each behavioral addiction is characterized by a recurrent pattern of behavior that has this essential feature within a specific domain. The repetitive engagement in these behaviors ultimately interferes with functioning in other domains. In this respect, the behavioral addictions resemble substance use disorders. Individuals with substance addictions report difficulties in resisting the urge to drink or use drugs.

Behavioral and substance addictions have many similarities in natural history, phenomenology, and adverse consequences. Both have onset in adolescence and young adulthood and higher rates in these age groups than among older adults (5). Both have natural histories that may exhibit chronic, relapsing patterns, but with many people recovering on their own without formal treatment (so-called "spontaneous" quitting) (6). 
Behavioral addictions are often preceded by feelings of "tension or arousal before committing the act" and "pleasure, gratification or relief at the time of committing the act" (4). The ego-syntonic nature of these behaviors is experientially similar to the experience of substance use behaviors. This contrasts with the ego-dystonic nature of obsessivecompulsive disorder. However, both behavioral and substance addictions may become less ego-syntonic and more ego-dystonic over time, as the behavior (including substance taking) itself becomes less pleasurable and more of a habit or compulsion $(2,7)$, or becomes motivated less by positive reinforcement and more by negative reinforcement (e.g., relief of dysphoria or withdrawal).

Behavioral and substance addictions have phenomenological similarities. Many people with behavioral addictions report an urge or craving state prior to initiating the behavior, as do individuals with substance use disorders prior to substance use. Additionally, these behaviors often decrease anxiety and result in a positive mood state or "high", similar to substance intoxication. Emotional dysregulation may contribute to cravings in both behavioral and substance use disorders (8). Many people with pathological gambling, kleptomania, compulsive sexual behavior, and compulsive buying report a decrease in these positive mood effects with repeated behaviors or a need to increase the intensity of behavior to achieve the same mood effect, analogous to tolerance (9-11). Many people with these behavioral addictions also report a dysphoric state while abstaining from the behaviors, analogous to withdrawal. However, unlike substance withdrawal, there are no reports of physiological prominent or medically serious withdrawal states from behavioral addictions.

Pathological gambling, the most thoroughly studied of the behavioral addictions, provides further insight into the relationship of behavioral addictions and substance use disorders (see also Wareham and Potenza, this issue). Pathological gambling usually begins in childhood or adolescence, with males tending to start at an earlier age $(5,12)$, mirroring the pattern of substance use disorders. Higher rates of pathological gambling are observed in men, with a telescoping phenomenon observed in females (i.e., women have a later initial engagement in the addictive behavior, but foreshortened time period from initial engagement to addiction) (13). The telescoping phenomenon has been extensively documented in a variety of substance use disorders (14).

As in substance use disorders, financial and marital problems are common in behavioral addictions. Individuals with behavioral addictions, like those with substance addictions, will frequently commit illegal acts, such as theft, embezzlement, and writing bad checks, to either fund their addictive behavior or cope with the consequences of the behavior (15).

\section{Personality}

Individuals with behavioral addictions and those with substance use disorders both score high on self-report measures of impulsivity and sensation-seeking and generally low on measures of harm avoidance (16-20). However, individuals with some behavioral addictions, such as internet addiction or pathological gambling, may also report high levels of harm avoidance (21; see also Weinstein and Lejoyeux, this issue). Other research has suggested that aspects of psychoticism, interpersonal conflict, and self-directedness may all play a role in internet addiction (see Weinstein and Lejoyeux, this issue). In contrast, individuals with obsessive compulsive disorder generally score high on measures of harm avoidance and low on impulsivity $(17,21)$. Individuals with behavioral addictions also score high on measures of compulsivity, but these may be limited to impaired control over mental activities and worries about losing control over motor behaviors (22). Impaired inhibition of motor responses (impulsivity) has been found in individuals with obsessive compulsive disorder and pathologic skin picking (a behavioral addiction with arguably closer phenomenological links to obsessive compulsive disorder), whereas cognitive inflexibility 
(thought to contribute to compulsivity) was limited to obsessive compulsivity disorder $(23,24)$.

\section{Comorbidity}

Although most nationally representative studies have not included assessment of behavioral addictions, existing epidemiological data support a relationship between pathological gambling and substance use disorders, with high rates of co-occurrence in each direction $(25,26)$. The St. Louis Epidemiologic Catchment Area (ECA) study found high rates of cooccurrence for substance use disorders (including nicotine dependence) and pathological gambling, with the highest odds ratios generally observed between gambling, alcohol use disorders, and antisocial personality disorder (25). A Canadian epidemiological survey estimated that the relative risk for an alcohol use disorder increased 3.8-fold when disordered gambling was present (27). Among individuals with substance dependence, the risk of moderate to high severity gambling was 2.9 times higher (28). Odds ratios ranging from 3.3 to 23.1 have been reported between pathological gambling and alcohol use disorders in U.S. population-based studies $(25 ; 29)$. Internet addiction was associated with harmful alcohol use (odds ratio of 1.84) in a study of 2,453 college students, after controlling for gender, age and depression (30).

Clinical samples of other behavioral addictions suggest that co-occurrence with substance use disorders is common (Table 1). These findings suggest that behavioral addictions may share a common pathophysiology with substance use disorders.

However, data about substance use comorbidity must be interpreted cautiously because any causal associations may manifest on a behavioral level (for example, alcohol use disinhibits a range of inappropriate behaviors, including those identified as addictive) or on a syndromal level (for example, a behavioral addiction starts after alcoholism treatment, possibly as a substitute for drinking). Problem gamblers with frequent alcohol use have greater gambling severity and more psychosocial problems resulting from gambling than those without alcohol use histories (31), and adolescents who are moderate to high frequency drinkers are more likely to gamble frequently than those who are not (32), suggesting a behavioral interaction between alcohol and gambling. In contrast, a similar finding regarding nicotine use suggests a syndromal interaction, as does the fact that adults with pathological gambling who are current or prior smokers had significantly stronger urges to gamble (33). Problem gamblers who use tobacco daily are more likely to have alcohol and drug use problems (34).

Other psychiatric disorders, such as major depressive disorder, bipolar disorder, obsessive compulsive disorder, and attention deficit hyperactivity disorder, are also commonly reported in association with behavioral addictions (35,36; see also Weinstein and Lejoyeux, this issue). However, many of these comorbidity studies were based on clinical samples. The extent to which these findings generalize to community samples remains to be determined.

\section{Neurocognition}

Behavioral addictions and substance use disorders may have common cognitive features. Both pathological gamblers and individuals with substance use disorders typically discount rewards rapidly (37) and perform disadvantageously on decision-making tasks (38) such as the Iowa Gambling Task, a paradigm that assesses risk-reward decision making (39). In contrast, a study of individuals with internet addiction demonstrated no such deficits in decision-making on the Iowa Gambling Task (40). A study using a comprehensive neurocognitive battery in 49 pathological gamblers, 48 abstinent alcohol-dependent subjects, and 49 controls found that gamblers and alcoholics both showed diminished performance on 
tests of inhibition, cognitive flexibility, and planning tasks, but had no differences on tests of executive functioning (41).

\section{Common Neurobiological Processes}

A growing body of literature implicates multiple neurotransmitter systems (e.g., serotonergic, dopaminergic, noradrenergic, opioidergic) in the pathophysiology of behavioral addictions and substance use disorders (42). In particular, serotonin (5-HT), which is involved with inhibition of behavior,, and dopamine, involved with learning, motivation, and the salience of stimuli, including rewards,, may contribute significantly to both sets of disorders $(42,43)$.

Evidence for serotonergic involvement in behavioral addictions and substance use disorders comes in part from studies of platelet monoamine oxidase B (MAO-B) activity, which correlates with cerebrospinal fluid (CSF) levels of 5-hydroxyindole acetic acid (5-HIAA, a metabolite of 5-HT) and is considered a peripheral marker of 5-HT function. Low CSF 5HIAA levels correlate with high levels of impulsivity and sensation-seeking and have been found in pathological gambling and substance use disorders (44). Pharmacologic challenge studies that measure hormonal response after administration of serotonergic drugs also provide evidence for serotonergic dysfunction in both behavioral addictions and substance use disorders (45).

The repetitive use of substances or engagement in a behavioral addiction following an urge may reflect a unitary process. Preclinical and clinical studies suggest that an underlying biological mechanism for urge-driven disorders may involve the processing of incoming reward input by the ventral tegmental area/nucleus accumbens/orbital frontal cortex circuit $(46,47)$. The ventral tegmental area contains neurons that release dopamine to the nucleus accumbens and orbital frontal cortex. Alterations in dopaminergic pathways have been proposed as underlying the seeking of rewards (gambling, drugs) that trigger the release of dopamine and produce feelings of pleasure (48).

Limited evidence from neuroimaging studies supports a shared neurocircuitry of behavioral addictions and substance use disorders (7). Diminished activity of the ventral medial prefrontal cortex (vmPFC) has been associated with impulsive decision making in riskreward assessments and with decreased response to gambling cues in pathological gamblers (49). Similarly abnormal vmPFC functioning has been found in people with substance use disorders (50). Game cue-associated brain activation in Internet gaming addicts occurs in the same brain regions (orbitofrontal, dorsolateral prefrontal, anterior cingulate, nucleus accumbens) as with drug cue-associated brain activation in drug addicts (51; see also Weinstein and Lejoyeux, this issue).

Brain imaging research suggests that the dopaminergic mesolimbic pathway from the ventral tegmental area to the nucleus accumbens may be involved in both substance use disorders and pathological gambling. Subjects with pathological gambling demonstrated less ventral striatal neuronal activity with fMRI while performing simulated gambling than did control subjects (52), similar to observations in alcohol-dependent subjects when processing monetary rewards (53). Diminished ventral striatal activation has also been implicated in the cravings associated with substance and behavioral addictions (41). Participation in a gambling task appears to elicit greater dopamine release in the ventral striatum in individuals with Parkinson's disease (PD) and pathological gambling than in individuals with PD alone (54), a response similar to that elicited by drug or drug-associated cues in drug addicts (55). 
Dopamine involvement in behavioral addictions is also suggested by studies of medicated PD patients $(56,57)$. Two studies of patients with PD found that more than $6 \%$ experienced a new onset behavioral addiction or impulse control disorder (e.g., pathological gambling, sexual addiction), with substantially higher rates among those taking dopamine agonist medication $(58,59)$. A higher levo-dopa dose equivalence was associated with greater likelihood of having a behavioral addiction (59). Contrary to what might be expected from dopamine involvement, antagonists at dopamine D2/D3 receptors enhance gambling-related motivations and behaviors in non-PD individuals with pathological gambling (60) and have no efficacy in the treatment of pathological gambling $(61,62)$. Further research is warranted to clarify the precise role of dopamine in pathological gambling and other behavioral addictions.

\section{Family History and Genetics}

Relatively few family history/genetics studies of behavioral addiction have been designed with appropriate control groups (7). Small family studies of probands with pathological gambling (63), kleptomania (64), or compulsive buying (65) each found that first-degree relatives of the probands had significantly higher lifetime rates of alcohol and other substance use disorders, and of depression and other psychiatric disorders, than did control subjects. These controlled family studies support the view that behavioral addictions may have a genetic relationship to substance use disorders.

The genetic versus environmental contributions to specific behaviors and disorders can be estimated by comparing their concordance in identical (monozygotic) and fraternal (dizygotic) twin pairs. In a study of male twins using the Vietnam Era Twin Registry, 12\% to $20 \%$ of the genetic variation in risk for pathological gambling and $3 \%$ to $8 \%$ of the nonshared environmental variation in risk for pathological gambling was accounted for by risk for alcohol use disorders (66). Two-thirds (64\%) of the co-occurrence between pathological gambling and alcohol use disorders was attributable to genes that influence both disorders, suggesting overlap in the genetically transmitted underpinnings of both conditions. These findings are similar to those suggesting common genetic contributions to a range of substance use disorders (67).

There are very few molecular genetic studies of behavioral addictions. The D2A1 allele of the D2 dopamine receptor gene (DRD2) increases in frequency from individuals with nonproblematic gambling to pathological gambling and co-occurring pathological gambling and substance use disorders (68). Several DRD2 gene single nucleotide polymorphisms (SNPs) have been associated with personality measures of impulsivity and experimental measures of behavioral inhibition in healthy volunteers (69), but these have not been evaluated in people with behavioral addictions. Excessive internet users had higher frequencies of the long-arm allele (SS) of the serotonin transporter gene (5HTTLPR) than healthy controls, and this was associated with greater harm avoidance (70; see also Weinstein and Lejoyeux, this issue).

\section{Responsiveness to Treatment}

Behavioral addictions and substance use disorders often respond positively to the same treatments, both psychosocial and pharmacological. The 12-step self-help approaches, motivational enhancement, and cognitive behavioral therapies commonly used to treat substance use disorders have been successfully used to treat pathological gambling, compulsive sexual behavior, kleptomania, pathologic skin picking, and compulsive buying (71-74). Psychosocial interventions for both behavioral addictions and substance use disorders often rely on a relapse prevention model that encourages abstinence by identifying patterns of abuse, avoiding or coping with high risk situations, and making lifestyle changes 
that reinforce healthier behaviors. In contrast, successful psychosocial treatments for obsessive-compulsive disorder emphasize exposure and response prevention strategies (2).

There are no medications currently approved for the treatment of behavioral addictions, but some medications that have shown promise in treating substance use disorders have also shown promise in treating behavioral addictions (75). Naltrexone, a mu-opioid receptor antagonist approved by the US Food and Drug Administration for the treatment of alcoholism and opioid dependence, has shown efficacy in controlled clinical trials for the treatment of pathological gambling and kleptomania (76-79), and promise in uncontrolled studies of compulsive buying (80), compulsive sexual behavior (81), internet addiction (82), and pathologic skin picking (83). These findings suggest that mu-opioid receptors play a similar role in behavioral addictions as they do in substance use disorders, possibly through modulation of the dopaminergic mesolimbic pathway. In contrast, the short-acting muopioid receptor antagonist naloxone exacerbates symptoms in obsessive-compulsive disorder (84).

Medications that alter glutamatergic activity have also been used to treat both behavioral addictions and substance dependence. Topiramate, an anti-convulsant which blocks the AMPA subtype of glutamate receptor (among other actions), has shown promise in openlabel studies of pathological gambling, compulsive buying, and compulsive skin picking (85), as well as efficacy in reducing alcohol (86), cigarette (87), and cocaine (88) use. Nacetyl cysteine, an amino acid that restores extracellular glutamate concentration in the nucleus accumbens, reduced gambling urges and behavior in one study of pathological gamblers (89), and reduces cocaine craving (90) and cocaine use (91) in cocaine addicts. These studies suggest that glutamatergic modulation of dopaminergic tone in the nucleus accumbens may be a mechanism common to behavioral addiction and substance use disorders (92).

\section{Diagnostic Issues}

Only one behavioral addiction, pathological gambling, is a recognized diagnosis in DSM-IV and ICD-10. Its diagnostic criteria are conceptually similar to those for substance abuse/ dependence, i.e., preoccupation with the behavior, diminished ability to control the behavior, tolerance, withdrawal, and adverse psychosocial consequences. The DSM-V Task Force has suggested moving pathological gambling from its current classification as an impulse control disorder to a new classification tentatively termed "Addiction and Related Disorders," which would include both substance use disorders and "non-substance addictions" (www.dsm5.org, accessed Feb. 10, 2010). The only substantive proposed change in diagnostic criteria is dropping of the criterion regarding commission of illegal acts to finance gambling, which was found to have low prevalence and little effect on the diagnosis.

Several other behavioral addictions have proposed diagnostic criteria, including compulsive buying (93), Internet addiction (94), video/computer game addiction (95), sexual addiction (96), and excessive tanning (see Kouroush et al., this issue). These are usually based on the existing DSM-IV criteria for substance abuse or dependence, e.g., excessive time spent in the behavior, repeated unsuccessful attempts to cut down or stop the behavior, diminished control over the behavior, tolerance, withdrawal, and adverse psychosocial consequences. The DSM-V Substance-Related Disorders work group is considering several of these nonsubstance addictions for inclusion in DSM-V, specifically mentioning Internet addiction (www.dsm5.org; accessed Feb. 10, 2010). However, for many of the disorders, there are little or no validating data for these diagnostic criteria; they are currently most useful as survey instruments to estimate the prevalence of the problem. 
One diagnostic question raised in the literature is where do behavioral addictions (and substance addictions) fall on an impulsivity-compulsivity dimension (97), i.e., are they more like impulse control disorders or obsessive compulsive disorders? Some have argued that this unitary dimension approach is overly simplistic, and that impulsivity and compulsivity represent orthogonal dimensions, rather than opposite poles of a single dimension (98). Consistent with the latter argument are findings such as substantial variation in degree of impulsivity among people with a behavioral addiction, variation that may be associated with response to pharmacological treatment $(48,99)$.

In DSM-IV, substance addictions (substance use disorders) are an independent category, while pathological gambling is considered an impulse control disorder, similar to, for example, pyromania and kleptomania. ICD-10 classifies pathological gambling as a "habit and impulse" disorder, but recognizes that "the behavior is not compulsive in the technical sense," even though it is sometimes called "compulsive gambling."

A related issue is the association, or clustering, if any, among different behavioral addictions. A cluster analysis of demographic and clinical variables in 210 patients with primary obsessive compulsive disorder identified two separate clusters of patients with behavioral addictions (100): patients with pathological gambling or sexual addiction ("hypersexuality") had earlier age of onset and were more likely male, as compared to patients with compulsive shopping. Further research is needed to confirm and extend this finding. One research approach that might substantially contribute to the field would be a comprehensive evaluation of a large, heterogeneous, well characterized group of individuals with various behavioral and substance addictions in terms of discrete components of impulsivity and compulsivity in both psychological (cognitive) and behavioral (motor) domains, e.g., sensitivity to reward delay (temporal discounting of reward), risk-reward decision-making, conceptual rigidity, premature anticipatory responding, perseverative responding, response inhibition, and reversal learning.

\section{Summary and Conclusions}

Growing evidence indicates that behavioral addictions resemble substance addictions in many domains, including natural history (chronic, relapsing course with higher incidence and prevalence in adolescents and young adults), phenomenology (subjective craving, intoxication ["high"], and withdrawal), tolerance, comorbidity, overlapping genetic contribution, neurobiological mechanisms (with roles for brain glutamatergic, opioidergic, serotonergic and dopamine mesolimbic systems), and response to treatment. However, existing data are most extensive for pathological gambling (see Wareham and Potenza, this issue), with only limited data for compulsive buying (see Lejoyeaux and Weinstein, this issue), internet addiction (see Weinstein and Lejoyeaux, this issue), and video/computer game addiction (see Weinstein, this issue), and almost no data for other behavioral addictions such as sexual addiction (see Garcia and Thibaut, this issue), love addiction (see Reynaud, this issue), pathologic skin picking (see Odlaug and Grant, this issue), or excessive tanning (see Kouroush et al., this issue). There is sufficient evidence to warrant considering pathological gambling as a non-substance or behavioral addiction; the DSM-V Task Force has proposed moving its classification in DSM-V from an impulse control disorder to an addiction and related disorders (a new category encompassing both substance-related and non-substance addictions).. In the current state of knowledge, especially in the absence of validated diagnostic criteria and prospective, longitudinal studies, it is still premature to consider other behavioral addictions as full-fledged independent disorders, much less classify them all as similar to substance addictions, rather than as impulse control disorders. Substantial future research, including both human and animal studies (101), is needed to bring our knowledge of behavioral addictions to the level of that for substance addictions, 
especially in the domains of genetics, neurobiology (including brain imaging), and treatment.

\section{Acknowledgments}

Supported by the Intramural Research Program, National Institutes of Health, National Institute on Drug Abuse; NIH (NIDA) grants R01 DA019139 (MNP) and RC1 DA028279 (JEG); and the Minnesota and Yale Centers of Excellence in Gambling Research, which are supported by the National Center for Responsible Gaming and its Institute for Research on Gambling Disorders. Dr. Weinstein is supported by the Israel National Institute for Psychobiology. The contents of the manuscript are solely the responsibility of the authors and do not necessarily represent the official views of the National Center for Responsible Gaming or the Institute for Research on Gambling Disorders or any of the other funding agencies.

\section{References}

1. Potenza MN. Should addictive disorders include non-substance-related conditions? Addiction. 2006; 101 (Suppl 1):142-151. [PubMed: 16930171]

2. Potenza MN, Koran LM, Pallanti S. The relationship between impulse-control disorders and obsessive-compulsive disorder: a current understanding and future research directions. Psychiatry Res. 2009; 170(1):22-31. [PubMed: 19811840]

3. Holden C. Behavioral addictions debut in proposed DSM-V. Science. 2010; 327:935. [PubMed: 20167757]

4. American Psychiatric Association. Diagnostic and Statistical Manual of Mental Disorders. 4. Washington, DC: American Psychiatric Publishing, Inc; 2000. text revision (DSM-IV-TR)

5. Chambers RA, Potenza MN. Neurodevelopment, impulsivity, and adolescent gambling. J Gambl Stud. 2003; 19(1):53-84. [PubMed: 12635540]

6. Slutske WS. Natural recovery and treatment-seeking in pathological gambling: results of two U.S. national surveys. Am J Psychiatry. 2006; 163(2):297-302. [PubMed: 16449485]

7. Brewer JA, Potenza MN. The neurobiology and genetics of impulse control disorders: relationships to drug addictions. Biochem Pharmacol. 2008; 75(1):63-75. [PubMed: 17719013]

8. de Castro V, Fong T, Rosenthal RJ, Tavares H. A comparison of craving and emotional states between pathological gamblers and alcoholics. Addict Behav. 2007; 32(8):1555-1564. [PubMed: 17174480]

9. Blanco C, Moreyra P, Nunes EV, Sáiz-Ruiz J, Ibáñez A. Pathological gambling: addiction or compulsion? Semin Clin Neuropsychiatry. 2001; 6(3):167-176. [PubMed: 11447568]

10. Grant JE, Brewer JA, Potenza MN. The neurobiology of substance and behavioral addictions. CNS Spectr. 2006; 11(12):924-930. [PubMed: 17146406]

11. Grant JE, Potenza MN. Gender-related differences in individuals seeking treatment for kleptomania. CNS Spectr. 2008; 13(3):235-245. [PubMed: 18323758]

12. Grant JE, Kim SW. Demographic and clinical features of 131 adult pathological gamblers. J Clin Psychiatry. 2001; 62(12):957-962. [PubMed: 11780876]

13. Potenza MN, Steinberg MA, McLaughlin SD, Wu R, Rounsaville BJ, O’Malley SS. Genderrelated differences in the characteristics of problem gamblers using a gambling helpline. Am J Psychiatry. 2001; 158(9):1500-1505. [PubMed: 11532738]

14. Brady KT, Randall CL. Gender differences in substance use disorders. Psychiatr Clin North Am. 1999; 22(2):241-252. [PubMed: 10385931]

15. Ledgerwood DM, Weinstock J, Morasco BJ, Petry NM. Clinical features and treatment prognosis of pathological gamblers with and without recent gambling-related illegal behavior. J Am Acad Psychiatry Law. 2007; 35(3):294-301. [PubMed: 17872548]

16. Lejoyeux M, Tassain V, Solomon J, Adès J. Study of compulsive buying in depressed patients. J Clin Psychiatry. 1997; 58(4):169-173. [PubMed: 9164428]

17. Kim SW, Grant JE. Personality dimensions in pathological gambling disorder and obsessivecompulsive disorder. Psychiatry Res. 2001; 104(3):205-212. [PubMed: 11728609]

18. Grant JE, Kim SW. Temperament and early environmental influences in kleptomania. Compr Psychiatry. 2002; 43(3):223-228. [PubMed: 11994842] 
19. Raymond NC, Coleman E, Miner MH. Psychiatric comorbidity and compulsive/impulsive traits in compulsive sexual behavior. Compr Psychiatry. 2003; 44(5):370-380. [PubMed: 14505297]

20. Kelly TH, Robbins G, Martin CA, Fillmore MT, Lane SD, Harrington NG, Rush CR. Individual differences in drug abuse vulnerability: d-amphetamine and sensation-seeking status. Psychopharmacology (Berl). 2006; 189(1):17-25. [PubMed: 16972106]

21. Tavares H, Gentil V. Pathological gambling and obsessive-compulsive disorder: towards a spectrum of disorders of volition. Rev Bras Psiquiatr. 2007; 29(2):107-117. [PubMed: 17639253]

22. Blanco C, Potenza MN, Kim SW, Ibáñez A, Zaninelli R, Saiz-Ruiz J, Grant JE. A pilot study of impulsivity and compulsivity in pathological gambling. Psychiatry Res. 2009; 167(1-2):161-168. [PubMed: 19339053]

23. Chamberlain SR, Fineberg NA, Blackwell AD, Robbins TW, Sahakian BJ. Motor inhibition and cognitive flexibility in obsessive-compulsive disorder and trichotillomania. Am J Psychiatry. 2006; 163(7):1282-1284. [PubMed: 16816237]

24. Odlaug BL, Grant JE, Chamberlain SR. Motor inhibition and cognitive flexibility in pathological skin picking. Prog Neuropharm Biol Psych. 2009 Nov 13. [Epub ahead of print].

25. Cunningham-Williams RM, Cottler LB, Compton WM 3rd, Spitznagel EL. Taking chances: problem gamblers and mental health disorders--results from the St. Louis Epidemiologic Catchment Area Study. Am J Public Health. 1998; 88(7):1093-1096. [PubMed: 9663161]

26. Petry NM, Stinson FS, Grant BF. Comorbidity of DSM-IV pathological gambling and other psychiatric disorders: results from the National Epidemiologic Survey on Alcohol and Related Conditions. J Clin Psychiatry. 2005; 66(5):564-574. [PubMed: 15889941]

27. Bland RC, Newman SC, Orn H, Stebelsky G. Epidemiology of pathological gambling in Edmonton. Can J Psychiatry. 1993; 38(2):108-112. [PubMed: 8467435]

28. el-Guebaly N, Patten SB, Currie S, Williams JV, Beck CA, Maxwell CJ, Wang JL. Epidemiological associations between gambling behavior, substance use \& mood and anxiety disorders. J Gambl Stud. 2006; 22(3):275-287. [PubMed: 17009123]

29. Welte JW, Barnes GM, Tidwell MC, Hoffman JH. The prevalence of problem gambling among U.S. adolescents and young adults: results from a national survey. J Gambl Stud. 2008; 24(2):119133. [PubMed: 18097737]

30. Yen JY, Ko CH, Yen CF, Chen CS, Chen CC. The association between harmful alcohol use and Internet addiction among college students: comparison of personality. Psychiatry Clin Neurosci. 2009; 63(2):218-24. [PubMed: 19335391]

31. Stinchfield R, Kushner MG, Winters KC. Alcohol use and prior substance abuse treatment in relation to gambling problem severity and gambling treatment outcome. J Gambl Stud. 2005; 21(3):273-297. [PubMed: 16134009]

32. Duhig AM, Maciejewski PK, Desai RA, Krishnan-Sarin S, Potenza MN. Characteristics of adolescent past-year gamblers and non-gamblers in relation to alcohol drinking. Addict Behav. 2007; 32(1):80-89. [PubMed: 16814934]

33. Grant JE, Potenza MN. Tobacco use and pathological gambling. Ann Clin Psychiatry. 2005; 17(4): 237-241. [PubMed: 16402757]

34. Potenza MN, Steinberg MA, McLaughlin SD, Wu R, Rounsaville BJ, Krishnan-Sarin S, George TP, O'Malley SS. Characteristics of tobacco-smoking problem gamblers calling a gambling helpline. Am J Addict. 2004; 13(5):471-493. [PubMed: 15764425]

35. Presta S, Marazziti D, Dell'Osso L, Pfanner C, Pallanti S, Cassano GB. Kleptomania: clinical features and comorbidity in an Italian sample. Compr Psychiatry. 2002; 43(1):7-12. [PubMed: 11788913]

36. Di Nicola M, Tedeschi D, Mazza M, Martinotti G, Harnic D, Catalano V, Bruschi A, Pozzi G, Bria P, Janiri L. Behavioural addictions in bipolar disorder patients: Role of impulsivity and personality dimensions. J Affect Disord. 2010 Jan 16.

37. Petry NM, Casarella T. Excessive discounting of delayed rewards in substance abusers with gambling problems. Drug Alcohol Depend. 56(1):25-32. [PubMed: 10462089]

38. Bechara A. Risky business: emotion, decision-making, and addiction. J Gambl Stud. 2003; 19(1): 23-51. [PubMed: 12635539] 
39. Cavedini P, Riboldi G, Keller R, D’Annucci A, Bellodi L. Frontal lobe dysfunction in pathological gambling patients. Biol Psychiatry. 2002; 51(4):334-341. [PubMed: 11958785]

40. Ko CH, Hsiao S, Liu GC, Yen JU, Yang MJ, Yen CF. The characteristics of decision making, potential to take risks, and personality of college students with Internet addiction. Psychiatry Res. 2010; 175:121-125. [PubMed: 19962767]

41. Goudriaan AE, Oosterlaan J, de Beurs E, van den Brink W. Neurocognitive functions in pathological gambling: a comparison with alcohol dependence, Tourette syndrome and normal controls. Addiction. 2006; 101(4):534-547. [PubMed: 16548933]

42. Potenza MN. Review. The neurobiology of pathological gambling and drug addiction: an overview and new findings. Philos Trans R Soc Lond B Biol Sci. 2008; 363(1507):3181-3189. [PubMed: 18640909]

43. Fineberg NA, Potenza MN, Chamberlain SR, Berlin HA, Menzies L, Bechara A, Sahakian BJ, Robbins TW, Bullmore ET, Hollander E. Probing compulsive and impulsive behaviors, from animal models to endophenotypes: a narrative review. Neuropsychopharmacology. 2010; 35(3): 591-604. [PubMed: 19940844]

44. Blanco C, Orensanz-Muñoz L, Blanco-Jerez C, Saiz-Ruiz J. Pathological gambling and platelet MAO activity: a psychobiological study. Am J Psychiatry. 1996; 153(1):119-121. [PubMed: 8540570]

45. Hollander E, Kwon J, Weiller F, Cohen L, Stein DJ, DeCaria C, Liebowitz M, Simeon D. Serotonergic function in social phobia: comparison to normal control and obsessive-compulsive disorder subjects. Psychiatry Res. 1998; 79(3):213-217. [PubMed: 9704868]

46. Dagher A, Robbins TW. Personality, addiction, dopamine: insights from Parkinson's disease. Neuron. 2009; 61(4):502-510. [PubMed: 19249271]

47. O'Sullivan SS, Evans AH, Lees AJ. Dopamine dysregulation syndrome: an overview of its epidemiology, mechanisms and management. CNS Drugs. 2009; 23(2):157-170. [PubMed: 19173374]

48. Zack M, Poulos CX. Parallel roles for dopamine in pathological gambling and psychostimulant addiction. Curr Drug Abuse Rev. 2009; 2(1):11-25. [PubMed: 19630734]

49. Potenza MN, Leung HC, Blumberg HP, Peterson BS, Fulbright RK, Lacadie CM, Skudlarski P, Gore JC. An FMRI Stroop task study of ventromedial prefrontal cortical function in pathological gamblers. Am J Psychiatry. 2003; 160(11):1990-1994. [PubMed: 14594746]

50. London ED, Ernst M, Grant S, Bonson K, Weinstein A. Orbitofrontal cortex and human drug abuse: functional imaging. Cereb Cortex. 2000; 10(3):334-342. [PubMed: 10731228]

51. Ko CH, Liu GC, Hsiao S, Yen JY, Yang MJ, Lin WC, Yen CF, Chen CS. Brain activities associated with gaming urge of online gaming addiction. J Psychiatr Res. 2009; 43(7):739-747. [PubMed: 18996542]

52. Reuter J, Raedler T, Rose M, Hand I, Gläscher J, Büchel C. Pathological gambling is linked to reduced activation of the mesolimbic reward system. Nat Neurosci. 2005; 8(2):147-148. [PubMed: 15643429]

53. Wrase J, Schlagenhauf F, Kienast T, Wüstenberg T, Bermpohl F, Kahnt T, Beck A, Ströhle A, Juckel G, Knutson B, Heinz A. Dysfunction of reward processing correlates with alcohol craving in detoxified alcoholics. Neuroimage. 2007; 35(2):787-794. [PubMed: 17291784]

54. Steeves TD, Miyasaki J, Zurowski M, Lang AE, Pellecchia G, Van Eimeren T, Rusjan P, Houle S, Strafella AP. Increased striatal dopamine release in Parkinsonian patients with pathological gambling: a [11C] raclopride PET study. Brain. 2009; 132(Pt 5):1376-1385. [PubMed: 19346328]

55. Bradberry CW. Cocaine sensitization and dopamine mediation of cue effects in rodents, monkeys, and humans: areas of agreement, disagreement, and implications for addiction. Psychopharmacology (Berl). 2007; 191(3):705-717. [PubMed: 17031707]

56. Weintraub D, Potenza MN. Impulse control disorders in Parkinson's disease. Curr Neurol Neurosci Rep. 2006; 6(4):302-306. [PubMed: 16822350]

57. Voon V, Fernagut P-O, Wickens J, Baunez C, Rodriguez M, Pavon N, Juncos JL, Obeso JA, Bezard E. Chronic dopaminergic stimulaton in Parkinson's disease: from dyskinesias to impulse control disorders. Lancet Neurol. 2009; 8:1140-1149. [PubMed: 19909912] 
58. Voon V, Hassan K, Zurowski M, de Souza M, Thomsen T, Fox S, Lang AE, Miyasaki J. Prevalence of repetitive and reward-seeking behaviors in Parkinson disease. Neurology. 2006; 67(7):1254-1257. [PubMed: 16957130]

59. Weintraub D, Siderowf AD, Potenza MN, Goveas J, Morales KH, Duda JE, Moberg PJ, Stern MB. Association of dopamine agonist use with impulse control disorders in Parkinson disease. Arch Neurol. 2006; 63(7):969-973. [PubMed: 16831966]

60. Zack M, Poulos CX. A D2 antagonist enhances the rewarding and priming effects of a gambling episode in pathological gamblers. Neuropsychopharmacology. 2007; 32(8):1678-1686. [PubMed: 17203013]

61. Fong T, Kalechstein A, Bernhard B, Rosenthal R, Rugle L. A double-blind, placebo-controlled trial of olanzapine for the treatment of video poker pathological gamblers. Pharmacol Biochem Behav. 2008; 89(3):298-303. [PubMed: 18261787]

62. McElroy SL, Nelson EB, Welge JA, Kaehler L, Keck PE Jr. Olanzapine in the treatment of pathological gambling: a negative randomized placebo-controlled trial. J Clin Psychiatry. 2008; 69(3):433-440. [PubMed: 18251624]

63. Black DW, Monahan PO, Temkit M, Shaw M. A family study of pathological gambling. Psychiatry Res. 2006; 141(3):295-303. [PubMed: 16499975]

64. Grant JE. Family history and psychiatric comorbidity in persons with kleptomania. Compr Psychiatry. 2003; 44(6):437-441. [PubMed: 14610719]

65. Black DW, Repertinger S, Gaffney GR, Gabel J. Family history and psychiatric comorbidity in persons with compulsive buying: preliminary findings. Am J Psychiatry. 1998; 155(7):960-963. [PubMed: 9659864]

66. Slutske WS, Eisen S, True WR, Lyons MJ, Goldberg J, Tsuang M. Common genetic vulnerability for pathological gambling and alcohol dependence in men. Arch Gen Psychiatry. 2000; 57(7):666673. [PubMed: 10891037]

67. Tsuang MT, Lyons MJ, Meyer JM, Doyle T, Eisen SA, Goldberg J, True W, Lin N, Toomey R, Eaves L. Co-occurrence of abuse of different drugs in men: the role of drug-specific and shared vulnerabilities. Arch Gen Psychiatry. 1998; 55(11):967-972. [PubMed: 9819064]

68. Comings DE. Why different rules are required for polygenic inheritance: lessons from studies of the DRD2 gene. Alcohol. 1998; 16(1):61-70. [PubMed: 9650637]

69. Hamidovic A, Dlugos A, Skol A, Palmer AA, de Wit H. Evaluation of genetic variability in the dopamine receptor D2 in relation to behavioral inhibition and impulsivity/sensation seeking: an exploratory study with d-amphetamine in healthy participants. Exp Clin Psychopharmacol. 2009; 17(6):374-383. [PubMed: 19968402]

70. Lee Y, Han D, Yang K, Daniels M, Na C, Kee B, Renshaw P. Depression-like characteristics of 5HTTLPR polymorphism and temperament in excessive internet users. Journal of Affective Disorders. 2009; 109 (1):165-169. [PubMed: 18045695]

71. Petry NM, Ammerman Y, Bohl J, Doersch A, Gay H, Kadden R, Molina C, Steinberg K. Cognitive-behavioral therapy for pathological gamblers. J Consult Clin Psychol. 2006; 74(3):555567. [PubMed: 16822112]

72. Teng EJ, Woods DW, Twohig MP. Habit reversal as a treatment for chronic skin picking: a pilot investigation. Behav Modif. 2006; 30(4):411-422. [PubMed: 16723422]

73. Mitchell JE, Burgard M, Faber R, Crosby RD, de Zwaan M. Cognitive behavioral therapy for compulsive buying disorder. Behav Res Ther. 2006; 44(12):1859-1865. [PubMed: 16460670]

74. Toneatto T, Dragonetti R. Effectiveness of community-based treatment for problem gambling: a quasi-experimental evaluation of cognitive-behavioral vs. twelve-step therapy. Am J Addict. 2008; 17(4):298-303. [PubMed: 18612885]

75. Dannon PN, Lowengrub K, Musin E, Gonopolsky Y, Kotler M. 12-month follow- up study of drug treatment in pathological gamblers: a primary outcome study. J Clin Psychopharmacol. 2007; 27(6):620-624. [PubMed: 18004130]

76. Kim SW, Grant JE, Adson DE, Shin YC. Double-blind naltrexone and placebo comparison study in the treatment of pathological gambling. Biol Psychiatry. 2001; 49(11):914-921. [PubMed: 11377409] 
77. Grant JE, Potenza MN, Hollander E, Cunningham-Williams R, Nurminen T, Smits G, Kallio A. Multicenter investigation of the opioid antagonist nalmefene in the treatment of pathological gambling. Am J Psychiatry. 2006; 163(2):303-312. [PubMed: 16449486]

78. Grant JE, Kim SW, Hartman BK. A double-blind, placebo-controlled study of the opiate antagonist naltrexone in the treatment of pathological gambling urges. J Clin Psychiatry. 2008; 69(5):783-9. [PubMed: 18384246]

79. Grant JE, Desai RA, Potenza MN. Relationship of nicotine dependence, subsyndromal and pathological gambling, and other psychiatric disorders: data from the National Epidemiologic Survey on Alcohol and Related Conditions. J Clin Psychiatry. 2009; 70(3):334-343. [PubMed: 19254518]

80. Grant JE. Three cases of compulsive buying treated with naltrexone. Int J Psychiatr Clin Practice. $2003 ; 7: 223-5$.

81. Raymond NC, Grant JE, Kim SW, Coleman E. Treatment of compulsive sexual behaviour with naltrexone and serotonin reuptake inhibitors: two case studies. Int Clin Psychopharmacol. 2002; 17(4):201-205. [PubMed: 12131605]

82. Bostwick JM, Bucci JA. Internet sex addiction treated with naltrexone. Mayo Clin Proc. 2008; 83(2):226-230. [PubMed: 18241634]

83. Arnold LM, Auchenbach MB, McElroy SL. Psychogenic excoriation. Clinical features, proposed diagnostic criteria, epidemiology and approaches to treatment. CNS Drugs. 2001; 15(5):351-359. [PubMed: 11475941]

84. Insel TR, Pickar D. Naloxone administration in obsessive-compulsive disorder: report of two cases. Am J Psychiatry. 1983; 140(9):1219-1220. [PubMed: 6614234]

85. Roncero C, Rodriguez-Urrutia A, Grau-Lopez L, Casas M. Antiepilectic drugs in the control of the impulses disorders. Actas Esp Psiquiatr. 2009; 37(4):205-212. [PubMed: 19927233]

86. Johnson BA, Rosenthal N, Capece JA, Wiegand F, Mao L, Beyers K, et al. Topiramate for treating alcohol dependence: a randomized controlled trial. JAMA. 2007; 298(14):1641-151. [PubMed: 17925516]

87. Johnson BA, Swift RM, Addolorato G, Ciraulo DA, Myrick H. Safety and efficacy of GABAergic medications for treating alcoholism. Alcohol Clin Exp Res. 2005; 29(2):248-254. [PubMed: 15714047]

88. Kampman KM, Pettinati H, Lynch KG, Dackis C, Sparkman T, Weigley C, et al. A pilot trial of topiramate for the treatment of cocaine dependence. Drug Alcohol Depend. 2004; 75(3):233-240. [PubMed: 15283944]

89. Grant JE, Kim SW, Odlaug BL. N-acetyl cysteine, a glutamate-modulating agent, in the treatment of pathological gambling: a pilot study. Biol Psychiatry. 2007; 62(6):652-657. [PubMed: 17445781]

90. LaRowe SD, Myrick H, Hedden S, Mardikian P, Saladin M, McRae A, et al. Is cocaine desire reduced by N-acetylcysteine? Am J Psychiatry. 2007; 164(7):1115-1117. [PubMed: 17606664]

91. Mardikian PN, LaRowe SD, Hedden S, Kalivas PW, Malcolm RJ. An open-label trial of Nacetylcysteine for the treatment of cocaine dependence: a pilot study. Prog Neuropsychopharmacol Biol Psychiatry. 2007; 31(2):389-394. [PubMed: 17113207]

92. Kalivas PW, Hu XT. Exciting inhibition in psychostimulant addiction. Trends Neurosci. 2006; 29(11):610-616. [PubMed: 16956674]

93. Black DW. Compulsive buying: a review. J Clin Psychiatry. 1996; 57 (Suppl 8):50- 54. [PubMed: 8698681]

94. Ko CH, Yen JY, Chen SH, Yang MJ, Lin HC, Yen CF. Proposed diagnostic criteria and the screening and diagnosing tool of Internet addiction in college students. Compr Psychiatry. 2009; 50(4):378-384. [PubMed: 19486737]

95. Porter G, Starcevic V, Berle D, Fenech P. Recognizing problem video game use. Aust N Z J Psychiatry. 2010; 44(2):120-128. [PubMed: 20113300]

96. Goodman A. Sexual addiction: designation and treatment. J Sex Marital Ther. 1992; 18(4):303314. [PubMed: 1291701]

97. Hollander E, Wong CM. Body dysmorphic disorder, pathological gambling, and sexual compulsions. J Clin Psychiatry. 1995; 56 (Suppl 4):7-12. [PubMed: 7713866] 
98. Lochner C, Stein DJ. Does work on obsessive-compulsive spectrum disorders contribute to understanding the heterogeneity of obsessive-compulsive disorder? Prog Neuropsychopharmacol Biol Psychiatry. 2006; 30(3):353-361. [PubMed: 16458405]

99. Grant, JE. Novel pharmacological targets for reward inhibition in pathological gambling. Presented at symposium on Translational Studies of Pathological Gambling at American College of Neuropsychopharmacology 48th Annual Meeting; Hollywood, FL. 2009.

100. Lochner C, Hemmings SM, Kinnear CJ, Niehaus DJ, Nel DG, Corfield VA, et al. Cluster analysis of obsessive-compulsive spectrum disorders in patients with obsessive-compulsive disorder: clinical and genetic correlates. Compr Psychiatry. 2005; 46(1):14-19. [PubMed: 15714189]

101. Potenza MN. The importance of animal models of decision making, gambling, and related behaviors: implications for translational research in addiction. Neuropsychopharmacology. 2009; 34(13):2623-2624. [PubMed: 19901921] 
Table 1

Lifetime Estimates of Substance use Disorders in Behavioral Addictions

\begin{tabular}{|l|l|}
\hline Behavioral Addictions & Lifetime Estimates of Substance Use Disorder \\
\hline Pathological Gambling & $35 \%-63 \%$ \\
\hline Kleptomania & $23 \%-50 \%$ \\
\hline Pathologic Skin Picking & $38 \%$ \\
\hline Compulsive Sexual Behavior & $64 \%$ \\
\hline Internet Addiction & $38 \%$ \\
\hline Compulsive Buying & $21 \%-46 \%$ \\
\hline
\end{tabular}

Source: Grant JE. Impulse Control Disorders: A Clinician's Guide to Understanding and Treating Behavioral Addictions New York, NY: Norton Press, 2008 . 